\title{
Female Perspective but Patriarchy Implication: The Illusory Sexual Subjectivity of Female Protagonist in Chipozi zhuan
}

\author{
CHU Hoi Yan ${ }^{1 *}$
}

\author{
${ }^{1}$ The University of Hong Kong, Hong Kong \\ *Corresponding author. Email: u3547750@connect.hku.hk
}

\begin{abstract}
Chipozi zhuan (Biography of a foolish woman) is an erotic novel in Ming dynasty, of which the female first person narrator makes it unique and eye-catching. Many studies have discussed this novel concerning its author's identity, delivery as well as images of sex and gender. Regarding the issue of female image, a common-seen view is that the female protagonist of Chipozi zhuan is placed as a role of victim, which rationalizes her sexual misconduct and criticizes the patriacrchal culture indirectly. However, narrations of Chipozi zhuan relative to active or passive sexual roles seem to reflect other implication about sex and gender. This article mainly focuses on the sexual subjectivity of the female protagonist in Chipozi zhuan, and adopts a text-centered inter-disciplinary methodology, which not only focuses on the original content of novel but also embrace perspectives and knowledge from feminism, sociological theory and historical materials. This kind of analysis show that female sexual subjectivity in Chipozi zhuan is illusory and constructed based on a male perspective, which mainly shown from three perspectives: the denial to female desire, the rationalization of male violence through depicting female pleasure in extreme passive sex as well as the association between social class and sex.
\end{abstract}

Keywords: Chipozi zhuan, female desire, sexual subjectivity, feminism, Ming-Qing fiction

\section{INTRODUCTION}

Previous researches about Chipozi zhuan mainly focused on its author's identity and its dissemination in different regions [8][11][15]. A number of scholars attempted to analyze this novel with a frame of gender and sex. For example, Sun Shaoxian regarded the female leading role $\mathrm{A} \mathrm{Na}$ in this story as a woman who actively strived for sexual rights and eventually became a sacrificial lamb to the patriarchal culture [14]. Martin W. Huang shared a similar idea that Chipozi zhuan circuitously criticized the patriacrchal oppression on females by placing $\mathrm{A} \mathrm{Na}$ in the position of a victim [9]. He also pointed out the association between political status and female power of sexual domination by comparing Chipozi zhuan with Ruyijun zhuan, and further stated that $\mathrm{A} \mathrm{Na}$ 's tragedy symbolizes the tragic termination of a persuit of lust by any common woman [9]. Although these studies discussed the female role and gender implication in Chipozi zhuan, few of them further explore subjectivity of the protagonists in a detailed way.
In Chipozi zhuan, A Na develops sexual relationships with twelve men besides her husband, and half of them are seduced by $\mathrm{A} \mathrm{Na}$ and remain a relatively passive position in their sexual relations, while the others actively surbonidate A Na. Chipozi zhuan provides active and passive sexual behaviors with different narratives, which reflects the author's attitude towards female desires and opinions on the relationship between class and sexual rights.

This article will discuss Ana's sexual subjectivity by analyzing her roles in sexual activities and try to uncover implications of sex and gender embedded in the author's narration through mainly three perspectives: firstly, analyzing how the original text of Chipozi zhuan denies female desire and active acquirement of sexual pleasure through its narration; secondly, discussing Ana's feeling in extremely passive sex like rape and exploring reasons behind such depiction; thirdly, exploring the association between sexual initiative and social classes through analyzing the active and passive sexual role of different protagonists. 


\section{DENIAL TO FEMALE DESIRE}

Chipozi Zhuan denies female desire progressively, which can describe in three stages: 1) showing the failure of active acquisition of sexual pleasure; 2) magnifying passivity as the only way for female sexual satisfaction; 3) punishing female with sexual desire and stressing the female fidelity to only one man.

\subsection{The Failure of Active Acquirement of Sexual Pleasure}

A Na has been actively seeking for sexual partners, which seems to break the stereotype of female passivity of sex and to declare rights on her own body [5]. However, the sexual experience sought by A Na does not bring her pleasure but sufferings and dissatisfaction. For instance, although $\mathrm{A} \mathrm{Na}$ is the one who invites her younger cousin Hui Min to have sex, her feelings during this sexual activity is described as "pain like being punctured", "unbearable painful" and "strongly unhappy and wanted to stop" [4]. Moreover, Hui Min adopts a more aggressive sexual action when $\mathrm{A} \mathrm{Na}$ suffers so much that she wishes to stop, revealing the fact that $\mathrm{A} \mathrm{Na}$ eventually loses her initiative and can't enjoy sex as her male partner does even when she starts the sexual activity. The sexual activity between $\mathrm{A} \mathrm{Na}$ and Jun duplicates this model, in which A $\mathrm{Na}$ propositions the male role in the first place while eventually falls into a passive position. During the sex, Jun ignores A Na's rejection and pushily continues the intercourse that causes great sufferings, transforming the voluntary sexual relationship to a rape. In this sense, A Na fails to be an equal participant who enjoys sex but a sufferer who passively suffers from male violence.

In addition to show how A NA lost her subjectivity in sexual activities and became a passive sufferer to pain, Chipozi Zhuan also demonstrates some sexual activities during which A Na maintained an active role, and further denies the possibility for $\mathrm{A} \mathrm{Na}$ to attain active role in sex by magnifying her dissatisfactory experiences in these sexual activities. A Na's sex with Ying Lang and Xiang Chan are two typical examples. It is described in the novel that A Na felt pity and dissatisfactory to have sex with Ying Lang as his sexual capacity is so poor that can not provide A Na with long-lasting sexual pleasure. Such narration further strengthens the idea that it is impossible for women to acquire sexual satisfaction when they are playing an active role in sex. Moreover, although $\mathrm{A} \mathrm{Na}$ played an active role in the first sexual activity with Ying Lang, she lost her subjectivity in the second sex with Ying Lang, during which Ying Lang continued sexual actions regardless of $\mathrm{A} \mathrm{Na}$ 's rejections. In this sense, $\mathrm{A}$ $\mathrm{Na}$ failed to acquire sexual subjectivity again and could not gain pleasure from it even when she played an active sexual role.

\subsection{Passivity is the Only Pathway for Female Sexual Pleasure}

The frequent repetition of unsuccessful sexual experiences strongly reinforces the image of females' failures to sexually satisfy themselves, gradually building an airtight wall that blocks any possibility for woman to acquire enjoyable sex. While readers are disappointed again and again by such intense and frequent failures and start to feel helpless, the author points out a pathway for females to enjoy sex, namely being completely passive in sex. The successful sex between $\mathrm{A} \mathrm{Na}$ and Fei $\mathrm{Xu}$ is an example of this kind of sex, in which males occupy the unquestionable dominant power in the relationship. Specifically, Fei Xu started and practiced the major sexual activities like chosing their poses and leading A Na's behaviors. The author used the word "command" when describing Feixu and A Na's behaviors: Fei $\mathrm{Xu}$ commanded $\mathrm{A} \mathrm{Na}$ to sit, Fei $\mathrm{Xu}$ commanded $\mathrm{A} \mathrm{Na}$ to back to him..... In this narration, A Na becomes the receiver and respondant of Fei Xu's commands who completely loses the initiative in this sexual relation. Such enlarged disparity in status further denies the possibility that females can acquire pleasure in self-attained sex.

Females can only feel painful and dissatisfactory when they hold sexual subjectivity, while they can experience pleasure in passive sexual behaviors. Such depictions deny the possibility of female assertiveness and initiatives in sex through repeated presentation of unsuccessful female attempts to pursue sexual subjectivity.

\subsection{Denial to Female Desire: Punishment and Fidelity}

A $\mathrm{Na}$ actively develops sexual relationships with multiple males, which seems to share some similarities with the claim of whore feminism that women can resist male authority by refusing their bodies to be owned by the only one man [1]. However, it is clearly shown in prior examples that $\mathrm{A} \mathrm{Na}$ does not actually own her body in the sense that she can't achieve sexual satisfaction by herself. Gu Shengwu was the only sexual partner sought by $\mathrm{A} \mathrm{Na}$ that is able to provide $\mathrm{A} \mathrm{Na}$ with hedonic sex, but such enjoyable relationship eventually causes $\mathrm{A} \mathrm{Na}$ to be degraded and exiled. Patriarchal culture can always consolidate its voice by punishing females who do not fit in her role. A Na's miserable ending seems to imply such phallocentric view that denies female attempts of sexual expression of pursuit. It is common seen in novels during Ming and Qing dynasties that profligacy protagonists end with deaths or poor positions, which uncloses the danger of excessive desires and disorder caused by moral degeneration, serving as a warning. Jin Ping Mei (The Plum in the Golden Vase) is a representative of these novels. However, Chipozi zhuan deviates from this aim 
in a sense that no male characters receive punishments to their excessive desire and incestuous sexual activities while A Na carried all charges. Therefore, the only sin criticized by Chipozi Zhuan is female desire to equal sexual pleasure instead of human excessive desire, incest or moral degeneration.

In addition to that, $\mathrm{A} \mathrm{Na}$ tried to cut off relationships from other men once she meets Gu Shengwu, showing that she still builds her ultimate happiness on the fidelity to one particular man and fails to extricate from the destiny of letting her body be owned by a male. Ironically, A $\mathrm{Na}$ was not punished due to her licentious relationships with multiple men, but was degraded due to her fidelity to a particular man. A possible explanation for this narration is that woman was allowed to be " debauchery" or "sexually misconduct" as long as she fulfilled male desires, especially desires of men from higher social status, while she was banned to pursue her own sexual pleasure even if she practiced it with a quality expected by paternalism like fidelity.

\section{RATIONALIZATION OF MALE VIOLENCE: FEMALE GAINING PLEASURE FROM EXTREMELY PASSIVE SEXUAL ROLES}

The female protagonist in Chipozi zhuan was frequently placed in an extremely passive position during sex. More specificallu, a lot of sexual activities in Chipozi zhuan occur in a situation where the female is coerced to have sex. Martin W. Huang believes that such narrations victimize $\mathrm{A} \mathrm{Na}$, dispelling the negative connotations of $\mathrm{ANa}^{\prime}$ s sexual misbehaviors [9]. But on the other hand, the narration that $\mathrm{A} \mathrm{Na}$ feels pleasant when being raped could be seen as a rationalization of male violence. Plots of raping is repeatedly seen in Chipozi zhuan.

For instance, A Na' $\mathrm{s}$ brother-in-law threatens to expose $\mathrm{ANa}$ ' s secret affairs with other men unless she has sex with him. When A Na feels so insupportably painful that she begs to end the sexual activity, $\mathrm{ANa}^{\prime} \mathrm{s}$ brother-in-law penetrates more violently, magnifying the violent nature in this sexual contact. However, such violent treatment does not cause A Na to suffer further, but on the other hand, gives her pleasure. The fiction describes $\mathrm{A} \mathrm{Na}$ ' s mental state as such: “Although I felt painful, I started to realize some enjoyment from this sex" [4]. Victim' s pleasant sensation dispels the improperness of male' $s$ rape, transforming the one-side violent penetration to a voluntary sexual activity enjoyed by both participants.

The routine of " The female feels painful $\rightarrow$ the female refuses $\rightarrow$ the male continues $\rightarrow$ the female feels pleasant" recurs in multiple sexual activities in Chipozi zhuan. A Na' s sexual experience with Hui Min and the monk Hai both follow this routine. In such narration, female pain and rejection become something illusory that can easily be ignored because females will find sex enjoyable as long as the males continue to penetrate. Similar plots are frequently witnessed in modern pornography as well. More than half of erotic films contain verbal or physical violence towards females who usually respond indifferently and enjoyably just like A $\mathrm{Na}$ who "smiled" when being verbally threaten by Ke Tao and "looked happy" when being raped [10]. This kind of demonstrations signal that "women secretly wish to be raped" but relevant researches showed that most women preferred context-based sexual activities with equitable roles [2][10]. In Chipozi zhuan, A Na also prefers a relatively equitable sexual relationship with $\mathrm{Gu}$ Shengwu rather than other male-dominant affairs, corresponding to female need to be respected and to be treated equally. In light of that, enjoying rape is not a real experienced shared by most woman but a fevered imagination from a male gaze.

Violence is deeply rooted in the interactive effects among personal, environmental and social factors, which is closely associated with disorganized society, unequal gender environment and culture that rationalizes violence [3][10]. Ancient China is a feudal society that surbodinates women with patriarchy and hierarchy, which usually represents as "husband guides wife" and "women' s work centers around the home, men' s work centers around outside ", highlighting male dominant role and female subsidiary role [7]. Under this order, females become tradable products that serve as a secondary existence while men can enjoy ownerships of females according to their wealth and social status. This principle is demonstrated in Chipozi zhuan that $\mathrm{A} \mathrm{Na}$ could only place herself in a passive role when she faces men in a higher social class like her brother-in-law and father-in-law. Contemporaneous laws also play a role in strengthening the male-centered gender rules. To be more specific, a rapist will not be punished if he gains a permission from the victim' $s$ husband, because the sin of raping a woman is a damage to the benefits of another man' s properties rather than hurting a woman [12]. A society ignoring and depressing female subjectivities like that naturally rationalizes and supports gender-based violence.

To a large extent, these factors in the level of society, culture and laws contribute to the narratives rationalizing male violence in Chipozi zhuan. On the other hand, the spread and popularity of Chipozi zhuan, in turn strengthen the culture of gender inequality.

\section{PASSIVE AND ACTIVE: SOCIAL CLASS AND SEXUAL RIGHTS}

In Chipozi zhuan, whether A Na's sexual partners play an active or passive role in their relationships are 
closely linked to their social classes, which shows the strong association between social status and sexual rights. Sex partners that $\mathrm{A} \mathrm{Na}$ actively seeks for are all in a relatively lower social status compared with $\mathrm{ANa}$, such as her cousin Hui Min, the son of the old servant Jun, actor Xiang Chan and the poor student Gu Shengwu. Scholarly fame, official position and wealth all play an important role in one' s social status in Ming and Qing dynasties [6]. Plus, higher social status implies higher material standards of living, better quality of lives and more power. These advantages always attract women because these men can provide women with preferential treatment and better protection. Thus, when A Na does not actively proposition males in a higher social status, it is not that she is not attracted by these men, but that she is not allowed to play an active role in a relationship with men with a higher social status. Upper class men normally hold an absolute dominion over women' $\mathrm{s}$ bodies at that time. However, men can also overturn their disadvantages in social status by their sexual competence. For example, both $\mathrm{Da} \mathrm{Tu}$ and Ying Lang witness $\mathrm{A} \mathrm{Na}^{\prime}$ s secret affairs with other men, while Da $\mathrm{Tu}$ toughly participates in the in-progress sex with his good sexual ability when undersexed Ying Lang can only let out his sexual desire by masturbation.

Although men can acquire the sexual initiative with sexual competence, it is hard for lower-class men to gain the absolute sexual dominance, which can be seen by the comparison between A Na' s sexual relationship with Da Tu, Ying Lang and her sexual relationship with her father-in-law and sister-in-law. There are mainly two differences in these two relationships, which are the gender distribution and $\mathrm{A} \mathrm{Na}$ ' $\mathrm{s}$ feelings as a passive participant. Sexual activity led by $\mathrm{Da} \mathrm{Tu}$ and sex led by A Na's father-in-law both consist of three participants but the participants of the former are two men and one woman while the latter one are composed of two women and one man. Da Tu has to share one woman with another man, which is quite similar to the phenomenon of polyandry among the disadvantaged in Ming and Qing dynasties. When upper-class males enjoy the benefits of polygyny due to their wealth and status, men living in the bottom of society are too poor to "afford" multiple wives and concubine so they usually have to conduct " transactional polyandry", "conditional wife sale" or "retail proposition" to exchange living materials [13]. Although $\mathrm{A} \mathrm{Na}^{\prime}$ s relationship with $\mathrm{Da}$ Tu and Ying Lang is not in the range of marriage, the setting that lower-class men should share one woman' $\mathrm{s}$ body and higher-class man can enjoy multiple women still demonstrates the decisive role of social status in sex. Da Tu can become a dominant player in one sexual activity due to his sexual ability but he still can' t wholly own a woman' s body according to his social class.
A $\mathrm{Na}^{\prime} \mathrm{s}$ expressions in these two sexual activities also show the powerful influence of class on sex. A Na' s feeling is described as "unhappy all the time" when having sex with Da Tu and Ying Lang [4]. On the contrary, A Na feels fully delightful and sexually satisfied in the sexual activities with her father-in-law. In fact, $\mathrm{A} \mathrm{Na}$ remains a passive role in the sex with her father-in-law. When A Na is having sex with Da Tu and Ying Lang, she still can "ask Ying Lang to hold her to his knees", having alternatives for sex positions. During the sex with $\mathrm{A} \mathrm{Na}$ ' s father-in-law, her hands and legs are all fixed, leaving no possibility to choose or resist. It is very unnatural for $\mathrm{A} \mathrm{Na}$ to gain more sexual satisfaction under such circumstances, facing an aged partner with weaker sexual ability. In this sense, A Na' $\mathrm{s}$ pleasure in this sexual relationship is fabricated and shaped by the underlying power dynamics between her and her sex partners.

\section{CONCLUSION}

The female first person narrative and the representation of a female protagonist' s multiple sexual relationship in Chipozi zhuan make it look like a feminist work but the discussion about active and passive sexual roles in this fiction suggests that this work was deeply influenced by male-centered vision and thoughts. Its patriarchy implications are mainly shown in its triple denial to female desire through showing female unsuccessful attempts to actively pursue sexual pleasure, emphasizing passivity as the only way for female sexual pleasure and punishing females. Meanwhile, A Na' $\mathrm{s}$ enjoyable expressions in extremely passive sexual relationship demonstrate a fevered of female surbodination from a male gaze. Additionally, the corresponding relationship between sexual role and social status also shows the close association between social class and sexual rights.

\section{AUTHORS’ CONTRIBUTIONS}

This paper is independently completed by the author.

\section{ACKNOWLEDGMENT}

Thanks for Professor Wu Cuncun from the University of Hong Kong and Professor Wang from Brown University, who not only equipped me with necessary knowledge and technics to conduct literary studies but also inspire me on the topic and methodology of this article. Without their teaching and inspirations, I could not have come up with the idea of this article and eventually completed it. My sincere gratitude also goes to the teachers and students from the course of "Gender and sexuality in Ming and Qing fiction"at the University of Hong Kong, who shared their ideas openly and enlightened me a lot. 


\section{REFERENCES}

[1] Davidson, J., \& Layder, D. (1994). Methods, sex, and madness. London: Routledge.

[2] Fisher, W. A., \& Barak, A. (1991). Pornography, erotica, and behavior: More questions than answers. International Journal of law and Psychiatry, 14(1), 65-83.

[3] Flood, Michael, \& Pease, Bob. (2009). Factors Influencing Attitudes to Violence Against Women. Trauma, Violence \& Abuse, 10(2), 125-142.

[4] Furong zhuren. (1943). Chipozi zhuan [Chi pozi zhuan]. In Xiechunyuan Series [Xiechunyuan congkan]. Beijing: Xiechunyuan.

[5] Hite, S. (2006). Sexual behavior in the human female. Sexuality and Culture, 10(1), 49-62.

[6] Ho, P. (1962). The ladder of success in Imperial China: Aspects of social mobility, 1368-1911. New York, NY: Columbia University Press.

[7] Ho, Y. H. (2018). A study of women's roles in construction masculinities in Ming-Qing China. Taipei: Showwe Information Co., Ltd.

[8] Hu, L. Y. (2006). The question about Chipozi zhuan's auther [Chipozi zhuan de zuozhe wenti]. The research on Ming and Qing dynasties novels, 2006(1), 201-214.

[9] Huang, M. (2001). Desire and fictional narrative in late imperial China. Cambridge, MA: Harvard University Asia Center.

[10] Makin, D. A., \& Morczek, A. L. (2016). X Views and Counting. Journal of Interpersonal Violence, 31(12), 2131-2155.

[11] Shi, Y. (2012). The spread of Chipozi zhuan in Japan: discussion centering on Gao Luopei's manuscript [Chipozi zhuan zai riben de chuanbo: yi gaoluopei cangshouchaoben wei taolun zhongxin]. The journal of Ming-Qing fiction studies, 2012(3), 213-222.

[12] Sommer, M. (2000). Sex, law, and society in late imperial China. Stanford, CA: Stanford University Press.

[13] Sommer, M. (2015). Polyandry and wife-selling in Qing dynasty China: Survival strategies and judicial interventions. Oakland, CA: University of California Press.

[14] Sun, S. X. (2000). The death of heroes and the aging beauties [Yingxiong zhi si yu meiren chimu]. Beijing: Social sciences academic press.
[15] Yan, F. M. (2009). Understanding Ming-Qing erotic novels in a perspective of cultural communication: Taking "Chipozi"'s image as an example [Wenhua chuanbo shiyu Zhong de mingqing yanqing xiaoshuo: yi chipozi xingxiang wei li]. Southeast communication, 2009(5), 175-176. 